\title{
LA TRADICIÓN CLÁSICA \\ EN LA MÚSICA DE TOMÁS DE IRIARTE
}

\author{
José María Pérez Martel \\ CEPA Santa Cruz de Tenerife \\ jpermarm@gmail.com
}

\begin{abstract}
RESUMEN
El poema didáctico La Música del fabulista canario Tomás de Iriarte (1750-1791) contiene numerosas referencias a las lenguas clásicas y su cultura. Son una excelente muestra de la vasta cultura humanística y del dominio de las lenguas antiguas, y también modernas, que atesoraba Iriarte. En este trabajo analizamos el tratamiento que hace de personajes y temas de la historia, literatura y mitología de Grecia y Roma, y el modo en que vierte sus conocimientos de las lenguas clásicas en una obra suya, hoy olvidada, pero que reportó al escritor un reconocimiento internacional como gran teórico musical y constituye un digno botón de muestra de la literatura didáctica dieciochesca.

PalabRas ClaVE: Tradición clásica, Tomás de Iriarte, La Música, Ilustración, Neoclasicismo, poesía didáctica.
\end{abstract}

\section{THE CLASSICAL TRADITION IN TOMÁS DE IRIARTE'S LA MÚSICA}

\section{ABSTRACT}

The didactic poem The Music of the canarian fabulist Tomás de Iriarte (1750-1791) contains numerous references to the classical languages and their culture. They are an excellent example of the rich humanistic culture and knowledge of ancient and modern languages that Iriarte treasured. In this paper we analyze his treatment of characters and topics from the history, literature and mythology of Greece and Rome, and the way in which he pours his extensive knowledge of the classical languages into a work, now forgotten, but which gained him international recognition as a great musical theorist and constitutes a worthy sample of the eighteenth-century didactic literature.

KeYwords: Classical Tradition, Tomás de Iriarte, La Música, Enlightenment, Neoclassicism, Didactic Poetry.

Que Tomás de Iriarte es una de las figuras literarias más significativas del neoclasicismo español del siglo XVIII, es ya una cuestión fuera de toda duda. Su figura brilla por la vasta cultura humanística y la inteligencia, ocurrente e irónica a veces, y socarrona en otras ocasiones, que vierte en toda su diversa producción literaria. Es más 
conocido por sus Fábulas literarias (1782) que por el poema La Música (1780), en el que conjuga, a nuestro juicio, dos de sus facetas más destacadas: la de estudioso interesado por el dominio y conocimiento de las lenguas y sus propiedades y, por otra parte, la de músico poseedor de un dominio técnico a nivel teórico y práctico muy sobresaliente. Desde el punto de vista de la Filología Clásica, su poema interesa por la gran cantidad de referencias a la literatura, mitología y lenguas clásicas que contiene, y el tratamiento que hace de ellas, lo que pone de manifiesto tanto la sólida formación clásica grecolatina que poseía como la labor de escritor y traductor desarrollada desde muy joven.

\section{DATOS BIOGRÁFICOS DEL AUTOR}

La vida de Tomás de Iriarte es ya bien conocida gracias, entre otros, a los manuales y trabajos de Cotarelo y Mori (1897), Millares Carlo - Hernández Suárez (19751993), Russell P. Sebold (1961, 1978), Prieto de Paula (1992) y Martínez Mata - Pérez Magallón (2005). Contamos, además, con un documento de primera mano para conocer la mayor parte de su vida académica y pública hasta el año 1780. Se trata de las Apuntaciones que un curioso pidió a D. Thomás de Yriarte, acerca de su vida $y$ estudios, escritos en treinta de julio de 1780. Si bien el título parece indicar que se trata de un texto autobiográfico, hay quien se plantea dudas sobre su autoría y piensa que Iriarte puedo ser el curioso que solicitó la redacción del texto, o que probablemente sea iniciativa de su estrecho amigo Carlos Pignatelli, o incluso que lo escribiese el propio Iriarte sirviéndose de esta fórmula a modo de excusa, práctica corriente, por otra parte, en los escritos autobiográficos de la época (Durán López, 2005: 151). Este procedimiento fue imitado años más tarde, en 1799, por su paisano José de Viera y Clavijo, si bien no fue tan inmediata la publicación de su texto que vio la luz bajo la forma de memorias en 1866, cuando fueron publicadas en el tomo I de su Diccionario de Historia Natural (Martínez Hernández, 2006-2007: 396). El propio Viera, por otra parte, publicaba en 1783, aún en vida de Iriarte, en su Biblioteca de autores canarios, que aparece en el cuarto tomo, libro XIX de su Noticias de la Historia general de las Islas de Canaria (citamos por Cioranescu, A. introducción y notas, Goya Ediciones, tomo II, 1971, 925-928), unas notas biográficas de Iriarte que ponen de manifiesto la talla intelectual que ya poseía en vida nuestro escritor:

su ingenio, su fecundo numen y notorios talentos le han hecho muy célebre en cortos años dentro y fuera de España, por sus elegantes obras poéticas, su gusto y conocimiento de la música, su inteligencia en diferentes lenguas, su crítica y literatura. Hacer el simple catálogo de sus producciones sería elogiarle sin lisonja.

El texto del que hablamos, las Apuntaciones, está escrito en tercera persona, es breve y junto a los detalles biográficos, destaca especialmente el interés de Iriarte por detallar su producción literaria. Aparece en las primeras páginas del manuscrito 10.460 de la BNE titulado Obras poéticas de don Tomás de Iriarte, entresacadas de algunos de sus manuscritos, Madrid 1784. Lo citamos por la edición de Sebastián de la Nuez (1989, 12-19). Con la información de ese manuscrito más otros estudios 
sobre la obra y vida de Iriarte, redactamos estas breves notas biográficas, destacando aquellos aspectos que guardan más relación con el poema que analizaremos más adelante.

Tomás de Iriarte nace en el Puerto de la Cruz, Tenerife, el dieciocho de septiembre de 1750. Era hijo de don Bernardo de Iriarte y de doña Bárbara de las Nieves Remedios de Oropesa. A los diez años comenzó sus estudios de latín y filosofía con su hermano fray Juan Tomás de Iriarte, Maestro de la orden de Predicadores, y al cabo de dos años parece que traducía bastante bien a Cicerón, Virgilio y Ovidio y componía versos en latín. Cuando fue reclamado por su tío Juan de Iriarte (1702-1771), bibliotecario real y oficial traductor de la Secretaría de Estado, para que acudiese a formarse con él a Madrid, escribió unos dísticos latinos como despedida de Canarias que permitían entrever la gran competencia que tenía en el dominio de esa lengua. Su tío Juan había llegado a Madrid en 1724 a estudiar leyes, tras un periodo previo de formación en París y Londres, pero rápidamente abandona este plan, y tras un tiempo como preceptor de los hijos de los Duques de Béjar y de Alba, comenzó su carrera administrativa de escribiente segundo en 1726 y ascendió en la escala hasta llegar a bibliotecario primero en 1766. Desarrolló una intensa labor bibliográfica y se convirtió en un consumado helenista y latinista.

Al llegar Tomás de Iriarte junto a su tío en 1764, se instruye durante un intervalo de siete años en diversas materias humanísticas, dedicando especial empeño al aprendizaje del griego y del francés, y a la mejora del inglés y del latín, del que traduce al castellano muchos autores de retórica y poética, hacia las que ya mostraba especial predilección. Compone en esa época pequeños epigramas en latín sobre el contenido de sus lecturas juveniles. De forma autodidacta aprendió a tocar el violín y la viola, y adquirió conocimientos musicales a través de lecturas e instrucción que recibía de amigos y colegas, como es el caso del maestro de capilla Antonio Rodríguez de Hita (1722-1787).

A la muerte de su tío, en 1771, a la vez que perfecciona sus conocimientos de las lenguas italiana y alemana, pasa a ocupar su puesto como traductor de la Secretaría de Estado. La preparación y adiestramiento necesario para el puesto lo había realizado durante los tres años anteriores al sustituir a su tío en numerosas ocasiones, al tiempo que asistía todas las mañanas junto al Marqués de los Llanos a la Secretaría del Perú con la intención de formarse en el manejo de documentos y en el funcionamiento de la Administración. La capacidad intelectual de Iriarte, así como sus influencias políticas, debieron jugar un papel fundamental en la sustitución del empleo de su tío, cosa normal en la época (Perdomo Batista, 2010-2011: 199). Es precisamente a partir de entonces cuando desarrolla con intensidad su faceta de escritor y traductor, ganándose con el paso del tiempo el reconocimiento en los círculos culturales de Madrid. Escribe y publica diversos dramas, sainetes, poemas y cartas criticando los abusos y vicios de su época, al tiempo que escribe en latín inscripciones diversas, hoy conservadas, para espacios y monumentos públicos de Madrid y sus alrededores (García Jurado, 2013: 257). El 26 de junio de 1776 es nombrado archivero general del Consejo de Guerra, ocupación que le permitirá dedicar grandes ratos a la literatura. En 1777 traduce la Poética de Horacio y demuestra con ello el dominio que poseía del latín y del castellano. Su traducción permite, además, conocer 
sus métodos como traductor, bien analizados ya por los trabajos publicados del profesor Salas Salgado (1999, 2002, 2006 y 2007).

En los años siguientes sigue con una gran actividad intelectual y producción literaria: diseña, a instancia del conde de Floridablanca, un plan de estudios para una Academia de Ciencias y Buenas Letras y se encarga de la redacción de unas Lecciones instructivas sobre la historia y la geografía para niños, publicadas póstumamente en 1794; escribe sonetos, anacreónticas y poemas filosóficos y didácticos, como La Música (1780); traduce fábulas de Fedro y compone la égloga La felicidad de la vida en el campo (1780) que con el pseudónimo Francisco Agustín de Cisneros presentó a los premios de poesía de la Real Academia Española y con la que quedó en segundo lugar. La Academia adjudicó el primer premio a la égloga de Juan Meléndez Valdés, hecho que motivó que escribiese Reflexiones sobre la égloga intitulada Batilo para demostrar los escasos méritos que tenía esta. Escribe también en poco tiempo fábulas en verso reuniéndolas todas para su publicación en Fábulas literarias (1782). La gran fama que consigue con ellas va unida a las envidias y recelos que, según cuenta, le herían profundamente su carácter. A raíz de estas, se verá envuelto en severas polémicas literarias sobre su obra. Un buen ejemplo de esta cuestión es la dura sátira El asno erudito. Fábula original. Obra póstuma de un poeta anónimo que le dirige Juan Pablo Forner el mismo año de publicación de las Fábulas, y a la que Iriarte le responde, también bajo un pseudónimo, con la epístola Para casos tales, suelen tener los maestros oficiales. Epistola critico-parenética o exhortación patética que escribió don Eleuterio Geta al autor de las Fábulas literarias. Otra muestra de esas disputas es la crítica, escrita en latín macarrónico y también con el pseudónimo o anagrama de Matías del Retiro, a la pedagogía desfasada e ideas de escritores de su época vertida en Metrificatio invectivalis, obra en la que nuevamente vuelve a demostrar su sólida formación humanística y el perfecto dominio de la lengua latina (Salas Salgado, 1997: 333).

En esta última etapa de su vida, comienza a recopilar sus obras en verso y prosa y publicarlas, a partir de 1787, en la imprenta Benito Cano de Madrid bajo el título Colección de obras en verso y prosa de Tomás de Iriarte, llegando a seis volúmenes. Traduce cuatro libros de la Eneida virgiliana. Ya Viera en su Biblioteca de autores canarios (Goya ediciones, tomo II, 1971: 927) daba noticia de la traducción y lo consideraba uno de sus mayores futuros méritos. Lástima que no lo culminase:

Se sabe que trabaja actualmente la traducción en verso castellano de la toda la Eneida, y hay motivo fundado de esperar que éste será el más lozano de sus laureles.

A pesar del recrudecimiento de su enfermedad de hígado y los recurrentes ataques de gota, no deja de participar en la polémica entre los dramaturgos tradicionalistas y los neoclásicos que surge tras la publicación en 1785 de Tehatro español de Vicente García de la Huerta. Iriarte defiende la preceptiva clásica, y en esa línea escribe las comedias El señorito mimado (1787), La señorita malcriada (1788), El Don de gentes y Donde menos se piensa salta la liebre (1790). Su última obra fue el melólogo Guzmán el Bueno, soliloquio y escena trágica unipersonal con música en sus intervalos (1790). El texto y la música son suyos y para su composición 
se inspiró en Pygmalion (1762) de Rousseau, monólogo que combinaba música y declamación. Con respecto a sus producciones musicales, solo se conoce la música de su melólogo, y una colección de diecisiete cánones conservados en la Biblioteca del Conservatorio Superior de Música de Madrid y en alguna colección privada (Pérez Mancilla, 2018: 196-200). Sabemos que también compuso música y letra para tonadillas, villancicos y otros géneros populares, además de cuartetos y sinfonías concertantes, pero desafortunadamente estos últimos no se conservan. El 17 de septiembre de 1791 fallece en Madrid.

\section{HISTORIA DE LA COMPOSICIÓN DEL POEMA LA MÚSICA}

Con la publicación de La Música, Tomás de Iriarte obtuvo un gran reconocimiento como escritor especialista en la teoría de los sonidos en su país, siendo aún mucho mayor fuera de España. Su poema didáctico ha sido hasta la actualidad, de lo que puedo dar fe como estudiante de música que fui, manual de lectura y didáctica en los Conservatorios Profesionales y Superiores de Música de España, y en diversas instituciones de enseñanza musical de Europa y de América. Fue compuesto a instancias de su mecenas, el conde de Floridablanca. Cuando había escrito los tres primeros libros en 1778, tuvo que dejar su composición para responder a la mala crítica que había hecho Juan José López de Sedano a su traducción de la Poética horaciana del año anterior. Lo hizo en un librito escrito en quinces días titulado Donde las dan las toman, discurso joco-serio, y aprovechó su composición para insertar en él la traducción en verso de la primera sátira de Horacio. Retoma al poco la composición de los dos últimos capítulos del poema y las advertencias finales, logrando terminarlo en mayo de 1779. Antes de salir de la imprenta, Iriarte lee el manuscrito a diversos músicos de su círculo de amigos y lo corrige incansablemente. La cuidada selección de las láminas que iban a acompañar el texto de Iriarte, retrasó unos meses la publicación, que vio la luz en marzo de 1780 (Cotarelo y Mori, 1897: 202). El que la portada lleve la fecha 1779, puede deberse a que el texto del poema pudo imprimirse antes de que se entregasen y se imprimiesen las láminas que lo acompañaban, saliendo a la luz todo el poema finalmente al año siguiente. Ese mismo año recibe reseñas y comentarios de músicos y escritores muy elogiosos en revistas y periódicos extranjeros, especialmente en Italia, donde el poeta y libretista Pietro Metastasio (1698-1782), tras recibir un ejemplar del poema y una carta de Iriarte, alaba la exactitud y conocimiento del asunto tratado así como la elegancia y sencillez del estilo. Iriarte le responde con una carta en verso comparando el juicio del poeta italiano sobre su obra con el dictamen hecho por Apolo, Horacio, Anacreonte, Sófocles o el mismísimo Virgilio (Cotarelo y Mori 1897: 207). Parece que esta carta de Metastasio suscitó envidias y recelos en los círculos culturales madrileños, y ello motivó que Iriarte escribiese una de las tres fábulas póstumas que conservamos, El canario y el grajo, en la que es fácil adivinar quién es el canario y quiénes los grajos envidiosos (Poggio Capote - Regueira Benítez, 2012: 257).

Iriarte proyectó la composición de su obra concibiéndola como un entretenimiento personal dirigido a músicos no profesionales y público no especializado, 
práctica común, según parece, en los tratados musicales del siglo XVIII (García Arévalo, 2015: 40). Así lo confiesa en el «Prólogo» (todas las citas del texto de Iriarte en nuestro trabajo están tomadas de la edición príncipe de 1779, La Música, poema. por D. Tomas de Yriarte, Imprenta real de la Gazeta, Madrid):

I. Desde que concebí el proyecto de escribir el presente Poema sobre la Música, resolví por mui fundadas razones abstenerme de dar a luz una obra, que, sin captar aplausos del público, ni provocar su censura, debía servir privadamente sólo para mi diversión, y acaso para la de algunos Amigos aficionados al arte músico. Este era por cierto mi propósito, y en efecto le hubiera cumplido, si un Personage que baxo el inmediato patrocinio de nuestro augusto Monarca se complace en fomentar á los estudiosos, no se hubiese dignado de alentarme á continuar y concluir mi Poema [...]

Ese personaje al que se refiere era el conde de Floridablanca, quien le animó a terminar el poema y ayudó en su publicación en calidad de mecenas. La ausencia de poemas y tratados didácticos serios y fundamentados sobre este arte fue el motivo que generó esta iniciativa (II), lo contrario que ocurría con la poesía, bien tratada en verso por poetas y tratadistas como Horacio (s. I a. C.) y Nicolas Boileau (16361711). Aprovecha Iriarte aquí para censurar a quienes le precedieron en su labor de redactar poemas didácticos sobre la música (III-IV), práctica común en otros escritos suyos. Solo dos autores merecen un poco de su atención: cita en primer lugar al P. Francisco Antonio Le Fevre, autor del poema latino Musica, Carmen (1704); le sigue el Abate Du Bos (Jean-Baptiste Dubos, 1670-1742), cuyo manual Réflexions critiques sur la poésie et la peinture (1719) contiene un poema en cuatro cantos dedicado casi en exclusiva a la situación de la música en Francia, pero carente de parte doctrinal. Por último, vierte palabras sumamente críticas (v) al elogio a la música que el poeta, dramaturgo y músico canario Bartolomé Cairasco de Figueroa (1538-1610) escribiera en el tomo II de su Templo Militante (1602-1614) como preámbulo a la vida del Papa León I el Magno. Para Iriarte, Cairasco es un claro ejemplo de escritor que trata asuntos cuyos principios desconoce, y que por ello riega sus versos de errores técnicos sobre el arte musical. Ante este panorama bibliográfico tan poco nutrido de escritores habilidosos, Iriarte justifica la necesidad de su poema y se autoproclama primer autor de un tratado en verso sobre la música, y por ello pide aceptación e indulgencia a los lectores, alegando en su favor el conocimiento y experiencia musical que posee para su desarrollo (VI-VII):

VI. Entiendo, pues, que en nuestra lengua Castellana no se ha publicado Poema alguno compuesto de propósito sobre la Música.

Iriarte se sirve en este «Prólogo» de diversos recursos y tópicos de gran tradición; algunos de ellos, propios de estos textos previos al poema, ya habían sido utilizados por el autor canario en su «Discurso preliminar» que precede a su traducción de la Ars poetica horaciana del año 1777 (Salas Salgado, 1999: 254-255). Y es que todo el poema en su conjunto parece ser susceptible de analizarse bajo un enfoque retórico, como más adelante veremos, en el que se pueda identificar tanto las partes de construcción de un texto o discurso retórico, como el uso continuo de fórmulas y recursos propios de la oratoria clásica (Álvarez Martínez, 1999: 435). 
La Música fue rápidamente traducida, al poco de su publicación, fuera de España al inglés, francés, alemán e italiano y gozó de gran y extensa reputación en círculos literarios y musicales nacionales y extranjeros. También fue difundido pronto en América, siendo reeditado en México (1785) y formando parte de los fondos bibliográficos de universidades y centros de estudio musical del continente americano (Quintana, 2007: 82).

\section{LA TRADICIÓN CLÁSICA EN LA MÚSICA}

Para el desarrollo de este capítulo seguimos la línea de investigación desarrollada por el profesor Marcos Martínez Hernández, consistente en el estudio de la pervivencia y tratamiento de la cultura clásica grecolatina principalmente en la primera historiografía canaria, pero también en poetas y novelistas de nuestras islas como Manuel Verdugo (1991), José de Viera y Clavijo (2006-2007), Juan Jesús Armas Marcelo (2010), Cristóbal Pérez del Cristo (2014), entre otros.

\section{A) ESCRITORES GRECOLATINOS Y CUESTIONES LITERARIAS}

Las citas de autores de la literatura clásica, ceñidas casi exclusivamente a escritores latinos, dan prueba de la sólida formación clásica de Iriarte. Presentan algunos errores textuales en los fragmentos en prosa, citados de forma incompleta, y también en los poéticos, y en ocasiones Iriarte, o la fuente que utiliza para citar, elimina términos del texto original. La cita puede aparecer de forma explícita en el poema, o traducida y adaptada al metro. En este último caso, Iriarte señala siempre en una nota el texto original. Podemos pensar que Iriarte contó con una antología de sentencias y máximas clásicas de confección propia para su uso personal, o que se sirvió de algún recurso bibliográfico similar que circulaba en su época y era de uso común entre los intelectuales de la época, pues estamos ante citas de larga tradición en la literatura de siglos anteriores.

El autor más citado es su admirado Cicerón, del que toma las siguientes líneas de De Oratore III, 197, para la portada bellamente ilustrada de su obra. Una cita muy apropiada para el tema que se propone tratar:

Nibil est [autem] tam cognatum mentibus nostris quam numeri atque voces, quibus [et] excitamur, [et] incendimur, [et] lenimur, [et] languescimus, [et] ad hilaritatem, [et] ad tristitiam saepe deducimur.

De la misma obra, en las advertencias del Canto V, pág. 110, v. 5, a propósito de los daños y molestias que en el oído cultivado puede ocasionar la repetición de una música «de mal gusto», cita Iriarte el siguiente pasaje ciceroniano:

Voluptatibus maximis fastidium finitimum est (De Oratore III, 100). 
Las otras dos citas de Cicerón las encontramos en el «Prólogo» del poema y en las advertencias del Canto III. La primera es de Academ. Quaest. II, 7:

Quam multa quae nos fugiunt in cantu, exaudiunt in eo genere exercuati.

Con esta cita Iriarte advierte que el objetivo de su libro no es otro más que el lector poco versado en música adquiera ciertas delicadezas propias de este arte. La del canto III (pág. 67, v. 10), adaptada al metro del poema, le sirve a Iriarte para señalar que solo el instrumentista que se equivoca en la ejecución recibe la censura del público, a diferencia de lo que pudiera suceder en otras artes:

Aures [auris], quarum est judicium superbissimum (Orator, 150).

Con respecto a Horacio, Iriarte se cita en dos ocasiones a sí mismo mediante el texto de su propia traducción de la Poética horaciana: en las "Advertencias» del Canto III, señala la necesidad de que el compositor respete en la música coral las características y propiedades de cada una de las voces humanas. Si no lo hiciese, se pueden confundir y produciría en el público un gran desconcierto:

Aetatis cuiusque nontandi [notandi] sunt tibi mores (Ars poetica, 156).

Las varias propiedades que inseparables son de las edades.

La otra cita horaciana en versión de Iriarte la hallamos en el Canto V, epígrafe VIII. Le sirve al escritor canario para censurar a los compositores e instrumentistas, poco versados en su arte, que no corrigen sus creaciones musicales o no practican lo necesario con su instrumento:

In vitium ducit culpae fuga, si caret arte (Ars poetica, v.31)

Que, sin el arte, quien un vicio evita en vicio no menor se precipita.

La Institutio oratoria de Marco Fabio Quintiliano es usada en dos ocasiones por Iriarte. Con la primera, en las «Advertencias» del Canto IV, advierte Iriarte que el ingenio y el buen arte pueden hacer que en la música se pueda aprobar lo que el buen juicio desaprueba. Es una paráfrasis muy particular del fragmento de Quintiliano:

atque eo perniciosissima quod abundant dulcibus vitiis (Inst. Orat. Cap. I, 10).

Con la segunda cita, situada en las «Advertencias» del Canto V, Iriarte elogia el uso de la claridad expositiva en cualquier texto que verse sobre el contenido teórico de la ciencia musical, por él así llamada: 
En el «Prólogo», epígrafe VIII, Iriarte justifica su poema indicando que solo tratará preceptos generales sobre el arte musical dado lo vasto de la materia y tratarse de un poema con un fin didáctico. Para ello se sirve del célebre verso de las Geórgicas de Virgilio:

Non ego cuncta meis amplecti versibus opto (Georg. II, 42)

Para ilustrar cómo la obertura de un drama musical puede predisponer al público un determinado estado ánimo y atención propicios para lo que ocurrirá en escena después, Iriarte cita en el Canto IV, epígrafe VI, al pintor Teón de Samos (s. IV a. C.) que recogió magníficamente en un cuadro a un hoplita griego en disposición de entrar en combate. El aire guerrero en el retrato era tal que nos predispone a pensar que se convirtió en un héroe bélico singular. Además, la presentación del cuadro se hizo acompañar por el toque de asalto de una trompeta. Con ello, la música hizo más real la imagen de aquel combatiente lanzándose al ataque. Así se debe proceder también con la música. En las Advertencias del Canto IV, Iriarte cita expresamente la procedencia de este pasaje: Varia Historia de Claudio Eliano, II, 44.

Por último, en las advertencias finales del Canto V, a propósito de la superioridad de la lengua castellana para el canto, frente a la italiana o francesa, Iriarte ironiza sobre el ridículo efecto nasal que se produce al pronunciar el grupo de consonantes - $n n$ - en francés, tal como hiciera el poeta latino Persio con los actores que representaban a protagonistas abandonados por sus amantes, y cita:

\section{Rancidulum quiddam balba de nare locutus (Persio, Sat. I, 30)}

La herencia literaria de los clásicos también la encontramos en otras cuestiones. El metro elegido para el poema es la silva, combinación libre sin número establecido de versos endecasílabos y heptasílabos. Su justificación, presente en «Prólogo», epígrafe XVI es la siguiente: se trata de un metro consonante, más fácil de recordar, y muy sonoro, apropiado para tratar el arte de los sonidos; pero sobre todo porque no establece un número determinado de versos, y en eso se asemeja al hexámetro grecolatino:

Si los hexámetros Griegos y Latinos logran aquella variedad enérgica que no fastidia ni descaece aun en el mas dilatado Poema, es principalmente porque en ellos no tuvieron los Homeros y los Virgilios la precisión de completar el sentido al cabo de cierto numero determinado de versos; y así, por exemplo, quando se les ofrecía componer una descripción, alargaban á su arbitrio los períodos, empleando muchos versos; quando escribían una máxima ó sentencia, se ceñían á uno ú dos; hacían punto final donde les parecía; y en suma, acomodaban la versificación á la cantidad de las cosas que tenían que decir.

De igual manera, Iriarte es heredero de la tradición clásica cuando trata de llamar la atención sobre la gran novedad que va a suponer su publicación en lengua castellana. Demanda, por ello, la benevolencia de los lectores en el momento de emitir un juicio sobre ella, alegando en su defensa, además de la novedad, también la dificultad del asunto tratado: 
VI. ...y si por ser nuevo este asunto, merece tal qual aceptación quien le emprende; por ser tan arduo, merece también alguna indulgencia quien, como yo, no le desempeñe acaso á satisfacción de los Lectores inteligentes y de acreditado buen gusto y á los quales pertenece exclusivamente dar voto fundado acerca de las obras del ingenio.

Estamos ante el tópico propio del preámbulo, que presenta cosas novedosas, y del que precisamente Virgilio, en Georg. III, 4-14, da muestra de su uso (Herreros Tabernero, 2005: 26-27). De igual manera, reminiscencia del horaciano docere delectando encontramos en el epígrafe XV del «Prólogo»: siendo consciente de la dificultad de la materia tratada, Iriarte ha procurado disminuirla introduciendo «varios episodios y ficciones poéticas (no mitológicas)», y también no tratando ciertas cuestiones musicales como los métodos usados para solfear, o el contrapunto. Con ello espera que el lector consiga un mediano conocimiento de ciertas delicadezas de este arte, y con eso dará por bien hecha su labor:

Si consigo este fin, que particularmente me he propuesto, daré por bien empleada mi tarea, celebrando ser útil en algo, aun a costa de errar en mucho.

Tanto la petición de indulgencia para la novedad que presenta don Tomás, como la máxima horaciana presentes en el «Prólogo» del poema, son ejemplos claros del uso de la captatio benevolentiae que busca la predisposición favorable hacia su obra de los lectores y la comprensión de los errores.

Tan pronto leemos los tres primeros versos del canto I nos llegan ya ecos épicos de la Antigüedad:

Las marabillas de aquel arte canto

Que con varia expresión, grata al oido,

Mide y combina el tiempo y el sonido.

Nos recuerdan los comienzos de los principales poemas épicos de la literatura grecolatina: la Ilíada, la Odisea, la Eneida y, de alguna manera, también el comienzo de las Geórgicas virgiliana, de la que Iriarte toma la estructura para redactar su poema didáctico. Así lo confiesa en las advertencias del Canto IV:

Está averiguado que los Griegos y Latinos cantaban sus versos constantemente; y por eso empezaban sus Poemas diciendo con propiedad: Yo canto. Los modernos conservamos la costumbre de principiar los nuestros del mismo modo, sólo por imitación de los antiguos; y á no ser porque la práctica ya recibida nos autoriza para ello, debiéramos escusarlo; pues aunque recitemos ó declamemos los versos con alguna diferencia de la prosa, no los entonamos de suerte que podamos darles nombre de verdadero canto.

El Canto II del poema es un episodio bucólico que transcurre entre pastores de la Arcadia. Un joven músico, de nombre Salicio, toma el aspecto de pastor y deseoso de conquistar a la hermosa Criséa, muy aficionada a la música, le explica los sentimientos y afectos que esta puede expresar en una exposición de carácter didáctico que abarca todo el Canto (Herreros Tabernero, 2005: 32). 
El género bucólico no era desconocido para Iriarte: como decíamos en las notas biográficas, había compuesto la égloga La felicidad de la vida del campo, presentada a la Real Academia en 1779, y anteriormente la silva La felicidad en el campo en 1773, de la que versiona varios fragmentos para la égloga anterior, que recibió un accessit de la Real Academia Española y fue publicada por la misma en 1780. Durante mucho tiempo esta égloga se ha considerado una obra de escasos méritos, sin embargo, es un excelente ejemplo del juego entre ficción utópica y realidad propio de la la literatura del siglo XVIII (Cano Ballesta, 1991: 10).

En el Canto IV, IV-XII Iriarte tiene un sueño en el que es guiado por el músico napolitano Niccolò Jommelli (1714-1774) a los Campos Elíseos. Allí asiste, junto a lo más selecto de los músicos europeos, a la exposición que el compositor italiano hace de la escena musical europea del momento, alabando las virtudes musicales de cada nación, e impartiendo, a la vez, una clase práctica de orquestación:

Así exclamaba yo; mas confundido

Entre serios discursos que el empeño

De tan amplia materia me ofrecía,

A un lento sueño me sentí rendido,

Que acaso, mas que sueño,

Fue rapto de agitada fantasía.

Creí que en un recinto delicioso,

Como aquel que la antigua Poësía

Llamó campos Elisios (venturoso

Albergue de almas justas y eminentes)

Insignes Griegos Músicos veía,

Latinos, y de siglos mas recientes

Otros diversos que la fama alaba.

Y que mi buena suerte

Allí me trasladó, quando llegaba

A aquel eterno suelo

El celebre Jommelli, cuya muerte

A Nápoles dexaba sin consuelo.

Tras la intervención de Jommelli, Iriarte, aprovechando la ocasión, señala al músico napolitano que España destaca por un género musical noble que combina discurso hablado con arias, la zarzuela, así como por la alegre y castiza tonadilla. Pero cuando se encuentra defendiendo estos géneros musicales, la imagen de Jommelli se desvanece y despierta del sueño:

Aun iba á proseguir, si de mi mente

No hubiese conocido el extravío,

Al volver de mi sueño ú desvarío,

Y ver desvanecida de repente,

Quando más me empeñaba en mi discurso,

De Jommelli la imagen aparente,

La de aquella región, y aquel concurso, 
El molde literario utilizado para este sueño de Iriarte lo encontramos en Somnium Scipionis de Cicerón, presente en De re publica, vi 9-29. Aquí Iriarte es Escipión Emiliano, protagonista de la obra de Cicerón, y el músico napolitano es su abuelo Publio Escipión Africano. Este, por un lado, enseña al nieto su destino, que es el de su propio país, y por otro, le explica las recompensas que aguardan a la virtud en la otra vida; también le describe el universo, y el lugar de la Tierra y el hombre dentro de este. Iriarte, en cambio, aprovecha para poner en boca de Jommelli sus propios conocimientos musicales. El final es muy diferente: en Cicerón el protagonista decide esforzarse en vida y salvar la patria para obtener el premio eterno de la contemplación del universo. Tras esa decisión, despierta plácidamente recordando lo soñado (VI 26). En Iriarte es más simple: el protagonista únicamente se queda perplejo ante la desaparición de la imagen soñada. El texto ciceroniano, convertido en libreto musical por Metastasio en 1735, fue utilizado como composición-homenaje de reyes y autoridades por célebres compositores del siglo XVIII como Mozart, Gluck, Hasse y el propio Jommelli (Pérez Martel, 2017-2018: 282-284). Con este sueño literario, Iriarte, gran conocedor de la escena musical de su época, rinde homenaje al músico italiano fallecido unos pocos años antes de la publicación del poema mediante el texto de Cicerón.

\section{B) Personajes y lugares de la mitología grecorromana}

En los primeros versos del Canto I encontramos una invocación a las divinidades y temas míticos relacionados con la música: Apolo y su coro de Musas, las Sirenas, la flauta de Pan, la invención de la trompeta, Terpandro, el río Leteo, Orfeo... Sin embargo, Iriarte los denomina "falsos númenes» y desprecia sus fábulas. Ya en el «Prólogo», epígrafe III, critica la obrita del P. Francisco Antonio Le Fevre sobre la misma materia, publicada en 1704, en modo alguno didáctica, y llena de "exornaciones mitológicas» alejadas de los principios musicales fundamentales. Se declara, pues, seguidor de las sólidas verdades de la «Sabia naturaleza» que le ha de inspirar y dictar sus principios:

Sabia Naturaleza, que al encanto

De la divina Música sensibles

Formaste las vivientes criaturas,

Díctame tus preceptos infalibles;

Que si tu luz y auxilio me aseguras,

Podrá el acento de la musa mia

Imitar de su asunto la harmonía.

Tú sola, tú me bastas; y no imploro

Fantásticas Deidades de la Grecia.

Quien te sigue, las fábulas desprecia;

No confía en Apolo, ni en su coro;

No invoca á las Sirenas; ni averigua

Si halló la flauta Pan, el Dios de Arcadía,

O la trompeta fue invención Paladia; 
Si á la cítara antigua

El náufrago Arïon la vida debe,

Y Terpandro apacigua

Con su lira el tumulto de una plebe;

$\mathrm{O}$ si, atrayendo los peñascos duros,

Sabe Anfión á Tébas poner muros,

Y suspender Orféo

A los hombres, las fieras, y el Letéo;

Otras verdades sólidas me llaman,

Y ellas, nó falsos Númenes, me inflaman.

Iriarte siembra los cinco Cantos de su poema con referencias a divinidades, lugares y asuntos míticos relacionados con el arte musical: el dios Apolo/Febo con su dorada cítara y las Musas (passim), Narciso y Eco junto con Melopea y Harmonía (I, VIII), Melpómene y Talía (IV, I), los Campos Elíseos (IV, IV) Harpócrates, el numen del silencio (V, I), Proteo (III, VII)... No olvida nuestro escritor nombrar a los principales personajes de la Antigüedad clásica presentes en libretos de óperas $\mathrm{y}$ composiciones musicales de diverso género de su siglo, especialmente los del denominado opera seria (IV, X):

De Aquíles y Alexandro la memoria,

La del pío Troyano,

La de Ciro, Catón, Tito y Adriano

Viven, mas que en los bronces y en la historia,

En las obras de Músicos divinos

Que ó gozan en la tierra su morada,

$\mathrm{O}$ ya de esta mansión afortunada.

Este tipo de espectáculo musical puso en escena en toda Europa durante el siglo XVIII pasiones y conflictos humanos representados por héroes míticos grecorromanos y, en menor medida, por personajes de la historia de Grecia y Roma junto con otros pertenecientes al antiguo Egipto, el fabuloso Oriente, el Antiguo Testamento y héroes de las Cruzadas (Pérez Martel, 2017: 593 y ss.). En España tradujeron los libretos de esas obras, pertenecientes en su mayoría al dramaturgo y poeta italiano Pietro Metastasio (1698-1782), ilustres dramaturgos de la época (José de Cañizares, Vicente Camacho, Nicolás González Martínez, Antonio de Zamora...). Paralelo a la producción de óperas españolas sobre textos italianos, contábamos en la época de Iriarte con la tradición musical de la zarzuela mitológica, desde que Calderón de la Barca estrenara El laurel de Apolo en 1657. A este género le dedica, como señalábamos anteriormente, una defensa al final del Canto IV. Junto con la nómina de personajes clásicos citados, también menciona Iriarte célebres compositores de este tipo de obras, y dedica laudatorias palabras al compositor alemán Christoph Willibald Gluck (1714-1787), reformador de la opera seria y uno de los creadores musicales más ilustre del siglo XVIII:

Lograron ser dignísimos vecinos:

Galupi, Vinci, Pergolese, Leo, Héndel, Pórpora, Lulli, Pérez, Feo, 
Trajeta, Mayo, Cáfaro, Piccini

El anciano Saxon, Nauman, Sacchini,

Paesielo, Anfossi, y ótros infinitos

Que no sólo han sabido con primores

Agradar en sus músicos escritos,

Sino hacer agradables los errores.

Y tú, inmortal Compositor de Alceste,

De Ifigenia, de Páris y de Elena,

Cantor Germano del Cantor de Tracia,

Gluck, inventor sublime, por quien este

Será ya el siglo de oro de la escena,

Quando Europa te pierda por desgracia.

Ch. W. Gluck, junto con el citado Niccolò Jommelli (cf. IV, IV-XII) y el austriaco Franz Joseph Haydn (1732-1809), amigo personal de Iriarte (cf. V, v), constituyen para Iriarte la tríada musical de su época. A los tres compositores les dedica extensas y elogiosas palabras en las advertencias de los cantos IV y V.

\section{C) Personajes y hechos históricos de Grecia y Roma}

Todas las referencias y observaciones hechas por Iriarte relacionadas con aspectos históricos de Grecia y Roma pertenecen al ámbito del arte musical y la dramaturgia grecolatinas. Son numerosas, y por ello citamos las más relevantes a título de ejemplo.

En el epígrafe I del canto III, el fabulista canario declara que en todos los pueblos de la Antigüedad la música era considerada un arte divino, y que se defendía a todo aquel que venerara la música y supiera tocar un instrumento:

Veremos que la Grecia

$\mathrm{Al}$ insigne Temístocles desprecia,

Porque ignora el manejo

De la lira: que Sócrates, ya viejo,

Los rudimentos de pulsarla aprende:

Que sus afanes bélicos suspende

El Hijo de Peleo

Para hallar en la cítara recreo:

Y nombre de divina á competencia

Recibe aquella ciencia

De Babilonios, Persas, Chinos, Tirios,

Egipcios, Celtas, Árabes y Asirios.

Hay una referencia (IV, III) al florecimiento de las artes en Atenas durante el siglo V a. C., el denominado "Siglo de Pericles». Iriarte destaca la unión indisoluble que había entonces entre música y poesía en las representaciones dramáticas de la época: 
Oh ! quien pudiera trasladarse ahora

Al siglo de la Grecia floreciente:

$\mathrm{Al}$ siglo en que la Música sonora

Compañera tan útil y frequente

Era de las dramáticas acciones

No mienten las antiguas tradiciones!

Su representación era cantada,

Conforme á los acentos de un idioma

Digno de la nación mas delicada.

El fabulista canario también informa de que en Roma el ilustre Mecenas (s. I a. C.) las protegió y defendió, pero tras las invasiones bárbaras posteriores, la música perdió un gran protagonismo en la vida cotidiana de las personas (I, IX). Solo con la aparición del canto gregoriano, una de las creaciones humanas más bellas, perfectas y divinas, los músicos llegaron a superar en inspiración a célebres poetas de la Antigüedad grecolatina como Homero, Píndaro, o incluso el mismísimo Virgilio (III, V).

Cuestiones históricas y musicales más técnicas las encontramos diseminadas por los cinco cantos: el recitativo acompañado de música permite expresar mejor las emociones y pasiones humanas, como las óperas serias en las que la reina egipcia Berenice es protagonista en todo el siglo XVIII (IV, VII); en la antigua Grecia se denominaba "melopea» al arte de componer un canto con una melodía tan bella que permitiese guardarla mejor en la memoria ("Advertencias» del Canto I); las pausas y esperas en la música pueden servir de mucho para el efecto que pretende conseguir el compositor, igual que en pintura el griego Timantes (s. IV a. C.) hizo cuando pintó el sacrificio de Ifigenia (I, XII); cuestiones de teoría musical clásica como la diferencia que estableció la escuela de Pitágoras entre el compás-varón y el sonido-hembra, y que de la genial combinación de ambos solo surge la bella melodía (I, X). Para este último caso, la cita de Iriarte llega por transmisión indirecta y en las Advertencias del Canto I indica su fuente: se sirve del pasaje de Isaac Vossio (1618-1689), erudito holandés del siglo XVII, presente en su libro De poematum cantu et viribus rhythmi (1673), en el que precisamente trata de la alianza entre la poesía y la música:

Hinc est quod Pythagorici cantum feminam, rythmum vero marem appellent.

\section{D) Superioridad de la lengua CASTELlana PARA EL CANTO}

Ya en el epígrafe XIV del "Prólogo», Iriarte nos adelanta que la última advertencia del Canto V (pág. XXX de las «Advertencias») es una disertación sobre la aptitud de la lengua castellana para el canto. Busca nuevamente la captatio benevolentiae de los buenos lectores, a los que denomina "patricios», pues se trata de una causa muy justa y de gran interés. Sin embargo, la exposición de Iriarte se convierte en un denso y técnico análisis comparativo de determinados aspectos de morfología nominal de las lenguas italiana, castellana, latina y griega. Con este análisis demuestra nuevamente el escritor canario el sólido conocimiento de las peculiaridades fonológicas de esas lenguas, y la preocupación sobre las relaciones 
entre música y texto. Buena muestra de su habilidad y pericia en la combinación de la escritura musical y vocal es el melólogo Guzmán el Bueno (1790), mencionado anteriormente. Destacamos los siguientes aspectos lingüísticos relacionados con el castellano y las lenguas clásicas:

Según Iriarte, la lengua idónea para el canto será la que tenga más vocales que consonantes en sus palabras. Este es el caso del italiano y del castellano:

La suavidad de las voces de un idioma consiste principalmente en la abundancia de las vocales, porque ellas son las letras sonoras y cantables; $y$ las consonantes, que no pueden articularse por sí solas, únicamente sirven de retardar, ó confundir el sonido de las vocales. De este notorio principio resulta que la lengua que mas abunde en ellas, será la mas acomodada para el canto, como lo es sin disputa la Italiana, cuyas dicciones terminan ordinariamente en vocal. Lo mismo sucede, aunque nó con tanta freqüencia, en el Castellano.

Sobre la lengua latina, destaca los finales de palabras, que suelen llevar «consonantes duras» o incluso consonantes dobles, como también ocurre en francés e inglés. Estos finales de palabras no son, en modo alguno, idóneos para el canto:

Ademas de esto debe notarse que las consonantes en que acaban los vocablos Castellanos, son las menos duras; y así no tienen sus finales en B, ni en C, ó K, ni en F, ni en $G$, ni en LL, ni en $M$, ni en $P$, ni en T, como acontece en varias voces Latinas, v. g. ab, sub, ob; ac, sic, hoc, musam, dominum, sermonem; amat, monet, legit, sicut, en algunas Francesas, como sac, bec, public, chef, vif, travail, vermeil; cap, galop y en muchas Inglesas, como of, dog, book, drop. Mucho menos permite el Castellano terminaciones en dos ó más consonantes, como las hai, por exemplo, en las palabras Latinas est, ast, tune, stirps, frons, ars, plebs, urbs, falx, arx, amant y otras infinitas personas de verbos; o en las voces Francesas arc, tur, parc, musc, etc; o en las Inglesas world, storm, drink, etc; y en muchas alemanas, de lenguas derivadas del alemán.

El castellano, en cambio, presenta finales de palabras consonánticos «apacibles», muy aptos para el canto:

Exige, pues, la índole del idioma Castellano que sus vocablos terminen en las consonantes menos ásperas: v. g. en $\mathrm{D}$, que es mas suave que la $\mathrm{T}$, como merced, césped; en L, que lo es mas que la LL, como sutil, fácil; en N, como desden, numen; en R, (y nunca en RR) como amor, nácar, en S, como pais, cutis, y en Z, como feliz, cáliz. Las voces terminadas en $\mathrm{X}$ (pronunciándola guturalmente al modo que la J) son poquísimas, como carcax, relox; y así la aspereza que realmente tienen, no perjudica á la dulzura del total de la lengua. Si otras dicciones finalizan en las consonantes que se reprueban por duras, ó son nombres propios, por lo general exótico, como Jacob, Dantzick, ó son mui contadas como zenit, fagot, y alguna otra que difícilmente se encuentra.

Además de las consonantes, el castellano cuenta con cinco vocales de pronunciación y percepción clara y no confusa. Esto no ocurre con sonidos vocálicos del francés: 
Pero todavía restan observaciones que pueden confirmar este supuesto. Sea la primera que las cinco vocales $\mathrm{A}, \mathrm{E}, \mathrm{I}, \mathrm{O}, \mathrm{U}$, que entran en las sílabas del idioma Castellano, tienen, como en el Toscano, un sonido claro, lleno, señalado y constante, sin que admitamos aquellas vocales confusas y obscuras de que abunda, por exemplo, la lengua Francesa. Tales son la E muda, como en estas palabras: le, trouble, traitre; la U Francesa, como en éstas: füt, chute, jugé; y muchos diptongos de un sonido mixto y ambiguo, como en éstas: jeu, bosuf, orgueil, yeux, bruit, joindre, cuyas pronunciaciones son en extremo incómodas y desagradables para el canto. A todo esto se agrega en favor del Castellano, que de aquellas cinco vocales perfectas, las mas freqüentes en él son cabalmente la A y la $\mathrm{O}$, que se aventajan en sonoridad á las demás.

Por último, son los plurales de las palabras terminados en -as o en -es, los que dan a la lengua castellana la calidez al oído, a pesar de ser muy frecuentes, y una elegancia y majestuosidad solo comparable con el griego clásico:

Otra observación no menos importante es que en este idioma no domina con exceso consonante alguna defectuosa que pueda molestar los oidos; pues la que se halla mui repetida, particularmente en las terminaciones plurales, es la $S$; y ésta no sólo adquiere bastante variedad con la diversa inflexión en AS como Poetas, en ES como felices, y en OS como doctos, sino que da al lenguage una dignidad magestuosa, comparable á la del Griego, y admirada de muchos, principalmente del sabio Isaac Vosio en su tratado De Poematum cantu et viribus rythmi:

Fastum et ingenitam Hispanorum gravitatem horum quoque inesse sermoni facile quis deprehendat, siquis crebram repetitionem litterae A, vocalium longe magnificentissimae, ac ita prolixa illorum spectet vocabula. Sed et crebra finalis clausula $\mathrm{O}$ vel $\mathrm{OS}$ grande quid sonat.

(Citado en nota de la página XXXIII de las «Advertencias»).

\section{REFERENCIAS BIBLIOGRÁFICAS}

Álvarea Martínez, M. (1999): "La retórica en La Música de Tomás de Iriarte", Museo Canario Liv-I: 429-446.

Cano Ballesta, J. (1991): “Utopismo pastoril en la poesía dieciochesca: la Égloga de Tomás de Iriarte”, Anales de Literatura Española 7: 9-25.

Cotarelo y Mori, E. (2007): Iriarte y su época, Artemisa Ediciones [= Sucesores de Rivadeneira, 1897].

CurTius, E. R. (1984): Literatura europea y Edad Media Latina, FCE (=1948).

DURÁN LÓPEZ, F. (2005): Vidas de sabios. El nacimiento de la autobiografía moderna en España 1733-1848, CSIC, Madrid.

García-Arévalo Alonso, J. (2015): La impronta musical en la literatura hispana de la Ilustración. Don Lazarillo Vizcardi de Antonio Eximeno, Universidad de Salamanca [Tesis doctoral]. https://gredos.usal.es/bitstream/handle/10366/129408/DLEH_García-Arévalo AlonsoJ MúsicaLiteratura.pdf? sequence $=1$ \&isAllowed $=\mathrm{y}$

GARCía JURADO, F. (2013): "Latín y léxico de la Ilustración hispana. La obra epigráfica de Tomás de Iriarte", BRAE XCIII: 254-290.

Herreros Tabernero, E. (2005): "Las Geórgicas como modelo genérico en la literatura española", Cuadernos de Filología Clásica: Estudios Latinos 25 (2): 5-35. 
IrIARTE, T. DE (1779): La Música, poema, Imprenta Real de la Gazeta, Madrid.

IrIARTE, T. DE (2004a): La Música, Ediciones Idea, Santa Cruz de Tenerife.

IrIARTE, T. DE (2004b): La Música, poema por Tomás de Iriarte, Ayuntamiento de Madrid, Madrid.

LeZA CruZ, J. M. (2009): “El siglo XVIII: historia, instituciones, discursos”, en LeZA CruZ, J. M. (ed.), La música en el siglo XVIII, en C. CARREDANO - V. ELI RODRÍGUEZ (coords.), Historia de la música en España e Hispanoamérica, vol. 4, Madrid, FCE, pp. 29-123.

Martínez Hernández, M. (1991): "Cultura greco-latina y literatura canaria: el mundo clásico en Manuel Verdugo", en Homenaje al Profesor Sebastián de la Nuez, Servicio de Publicaciones de la Universidad de La Laguna, pp. 193-214. [= en Ensayos de Filología Clásica, Servicio de Publicaciones de la Universidad de La Laguna, 2001, pp. 225-253].

Martínez Hernández, M. (2006-2007): “La tradición clásica en un ilustrado canario: José de Viera y Clavijo", Estudios Canarios. Anuario del IECan 50-51 (1): 395-426.

Martínez Hernández, M. (2010): “La tradición clásica en J. J. Armas Marcelo: la mitología”, La Página 86: 55-143.

Martínez Hernández, M. (2014): "La tradición clásica en Cristóbal Pérez del Cristo (1639-1705): mito e historia”, Fortunatae 25: 315-322.

Martínez Mata, E. - Pérez Magallón, J. (2005): “Tomás de Iriarte, un ilustrado ejemplar”, en IriarTE, Tomás DE, Los literatos en Cuaresma, Biblioteca Nueva Oviedo, Universidad de Oviedo, pp. 9-91.

Millares Carlo, A. - Hernández Sú́rez, M. (1975-1993): Bibliografía de escritores canarios (siglos XVI, XVII y XVIII), Museo Canario, 6 vol.

Nuez Caballero, S. de la (1989): "Introducción" en Tomás DE IrIarTe, Fábulas literarias, Madrid, Viceconsejería de Cultura y Deportes, Gobierno de Canarias, pp. 1-22.

Nuez Caballero, S. DE la (2003): "La saga de los Iriarte. Tomás de Iriarte” en Y. Arencibia (coord.), Historia crítica. Literatura canaria, Las Palmas de Gran Canaria, pp. 357-384.

Perdomo-Batista, M. A. (2010-2011): "La ascensión de los Iriarte. A propósito de la relación entre políticos y literatos en la España del absolutismo borbónico", Philologica Canariensia 16-17: 193-220.

PéRez Mancilla, V. J. (2018): "La Música, pero también música: nuevos cánones de Tomás de Iriarte", Anuario Musical 73: 193-200.

Pérez Martel, J. Ma (2017): "Zarzuela barroca y mito clásico: Iphigenia en Tracia de Nicolás González

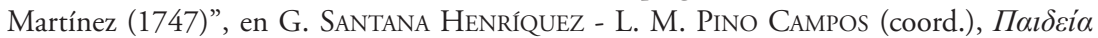

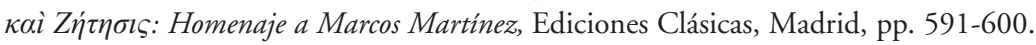

Pérez Martel, J. Ma (2017-2018): “El mundo clásico en las primeras óperas de Wolfgang Amadeus Mozart”, Fortunatae 28: 275-285.

Poggio Capote, M. - Regueira Benítez, L. (2012): "Las Fábulas literarias de Tomás de Iriarte en holandés (1833)", Cartas diferentes. Revista canaria de patrimonio documental 8: 253-261.

Prieto de Paula, A. L. (1992): “Introducción”, en Iriarte, T. DE, Fábulas literarias, Cátedra, Madrid, pp. $11-100$.

Quintana, H. J. (2007): "El poema La Música de Tomás de Iriarte: A propósito del cultivo del poema didascálico en la sociedad colonial caraqueña", Extramuros 28: 51-85.

Salas Salgado, F. (1997): "La Metrificatio Invectivualis de Tomás de Iriarte o un episodio de la Querelle des Anciens et des Modernes", Humanistica Lovaniensia 46: 326-362. 
Salas Salgado, F. (1999): "Observaciones sobre la traducción de Tomás de Iriarte de la Poética de Horacio”, en F. LAFARGA (ed.), La traducción en España (1750-1830). Lengua, literatura, cultura, Edicions de la Universitat de Lleida, pp. 253-262.

SAlas Salgado, F. (2002): La Ars poetica de Horacio en la versión de Tomás de Iriarte: justificaciones de método del traductor", Fortunatae 13: 281-294.

SAlas SAlgado, F. (2006): "Fuentes antiguas y modernas en la traducción de Tomás de Iriarte de la Poética de Horacio", Revista de Filología 24: 215-224.

SALAS SALGADO, F. (2007): Los clásicos latinos y su traducción en el siglo XVIII. Las reflexiones de Juan y Tomás de Iriarte, Ediciones Idea, Santa Cruz de Tenerife.

SEbold, R. P. (1961): “Tomás de Iriarte: poeta de «rapto racional»", Cuadernos de la Cátedra Feijoo 11: 9-67 [Número monográfico].

SEBOLd, R. P. (1978): “Introducción biográfica y crítica”, en Tomás DE IRIARTE, El señorito mimado. La señorita malcriada, Castalia Ediciones, Madrid, pp. 7-122.

Subirá PUIG, J. (1963): "El filarmónico D. Tomás de Iriarte”, Anuario de Estudios Atlánticos 9: 441-464. 
